\title{
Efeito do uso de protocolos metafiláticos segundo o risco de doença respiratória bovina em confinamentos
}

Layane Queiroz Magalhães[a]", Anderson Lopes Baptista ${ }^{[a]}$, Pedro de Almeida Fonseca ${ }^{[a]}$, Guilherme Lobato Menezes ${ }^{[a]}$, Geison Morel Nogueira ${ }^{[a]}$, Selwyn Arlington Headley ${ }^{[b]}$, Juliana Torres Tomazi Fritzen ${ }^{[b]}$, Amauri Alcindo Alfieri[ib], João Paulo Elsen Saut ${ }^{[a]}$

\footnotetext{
[a] Laboratório de Saúde em Grandes Animais, Faculdade de Medicina Veterinária, Universidade Federal de Uberlândia (UFU), Uberlândia, MG, Brasil

${ }^{[b]}$ Departamento de Medicina Veterinária Preventiva, Universidade Estadual de Londrina (UEL), Londrina, PR, Brasil
}

*Autor correspondente

e-mail: layanequeirozmagalhaes@gmail.com

\section{Resumo}

As doenças respiratórias dos bovinos (DRB) afetam negativamente índices produtivos por comprometer a saúde e bem-estar. Vários fatores que interferem na incidência, gravidade e implicações econômicas da DRB têm sido pesquisados, porém, no Brasil, a enfermidade ainda é pouco estudada. Ademais, a acurácia no diagnóstico da DRB é importante para aperfeiçoar o manejo e prevenção, auxiliando nos protocolos de tratamento. A hipótese é que o uso de protocolos metafiláticos, segundo o risco de DRB em bovinos confinados, reduz morbidade e lesões pulmonares ao abate. Objetivou-se avaliar o efeito de dois protocolos metafiláticos na morbidade e ocorrência de lesões pulmonares ao abate de bovinos confinados, além da participação de Manhheimia haemolytica, Histophilus somni, Herpesvírus bovino tipo-1 e vírus sincicial respiratório bovino, pelas técnicas de PCR e sequenciamento. Foram acompanhados 3.094 bovinos, machos, adultos, agrupados conforme o risco de DRB: a) grupo sem metafilaxia $(\mathrm{n}=2.104)$, animais de baixo risco; b) grupo metafilaxia com oxitetraciclina $(\mathrm{n}=789)$, risco moderado; c) grupo metafilaxia com tildipirosina $(n=201)$, alto risco. Animais com sintomatologia clínica de DRB foram identificados (DART System) e imediatamente tratados. 0 abate dos animais $(n=3.094)$ ocorreu em frigorífico fiscalizado pelo Serviço de Inspeção Federal, e as alterações pulmonares macroscópicas foram classificadas em escores adaptados de Bryant et al. (1990). A morbidade para DRB foi de 8,2\% (253/3.094) e houve menor frequência $(\mathrm{P}=0,019)$ em animais de risco moderado para DRB $(6,1 \%-48 / 789)$, seguido dos animais de alto risco com metafilaxia com tildipirosina $(6,5 \%$ - 13/201) e baixo risco sem metafilaxia $(9,1 \%-192 / 2.104)$. Sendo assim, esta ferramenta foi eficiente em reduzir os índices de morbidade da DRB, estando de acordo com o principal objetivo da mesma. No abatedouro, foram encontrados 1,2\% (37/3.094) de lesões pulmonares; 
destas, $18,9 \%$ (7/37) e 81,1\% (30/37) eram de animais com e sem DRB, respectivamente. Houve diferença $(P=0,036)$ na frequência de lesões entre animais sadios $(1,1 \%-30 / 2.841)$ e diagnosticados com DRB $(2,8 \%$ - 7/253), sendo o DART system eficiente em identificar os animais doentes, pois apenas $1,1 \%$ dos animais não tratados para DRB apresentaram lesões pulmonares. Foram identificados apenas os dois agentes bacterianos testados, M.haemolytica (16,2\%), considerado o patógeno bacteriano predominante na DRB, e H.somni (33,3\%), patógeno emergente, havendo 33,3\% de infecção concomitante. Os agentes virais testados e não encontrados na pesquisa muitas vezes predispõem a infecções bacterianas devido a uma imunossupressão, podendo estar associados ao período inicial de infecção, porém ausentes no momento de abate e avaliação. Concluiu-se que o uso de protocolos metafiláticos, de acordo com o risco de DRB, reduz morbidade e lesões pulmonares no abate, sendo as lesões mais frequentes em animais com DRB, e nelas identificados apenas os agentes bacterianos H. somni e M. haemolytica. 